\title{
ATIPINE EN PLAQUE TIPO MENINGIOMA. KLINIKINIS ATVEJIS
}

\author{
Dmitrij Aleksandrov \\ Klaipèdos universitetinès ligoninès Neurochirurgijos klinka, \\ Klaipédos universiteto Sveikatos mokslu fakulteto Visuomenès sveikatos katedra
}

Raktažodžiai: atipinis radiologinis vaizdas, en plaque tipo meningioma.

\begin{abstract}
Santrauka
Meningiomos tarp visų pirminių centrinės nervų sistemos (CNS) navikų pagal dažnumą užima antrają vietą ir sudaro 33,8 proc. visų intrakranijinių navikų atvejų. Nors $80-90$ proc. atvejų stebimas tipinis kompiuterinès tomografijos (KT) ir magnetinio rezonanso tomografijos (MRT) meningiomų vaizdas, tačiau iki 15 proc. atveju užfiksuojamas ir netipinis vaizdas. En plaque tipo meningiomos sudaro 2-9 proc. nustatomų meningiomų, tačiau dèl savo vaizdo ypatumų jos yra nemažas iššūkis, nustatant diagnozę ir parenkant gydymo taktiką. Straipsnyje aprašomas 53 metų amžiaus vyro en plaque tipo meningiomos klinikinis atvejis.
\end{abstract}
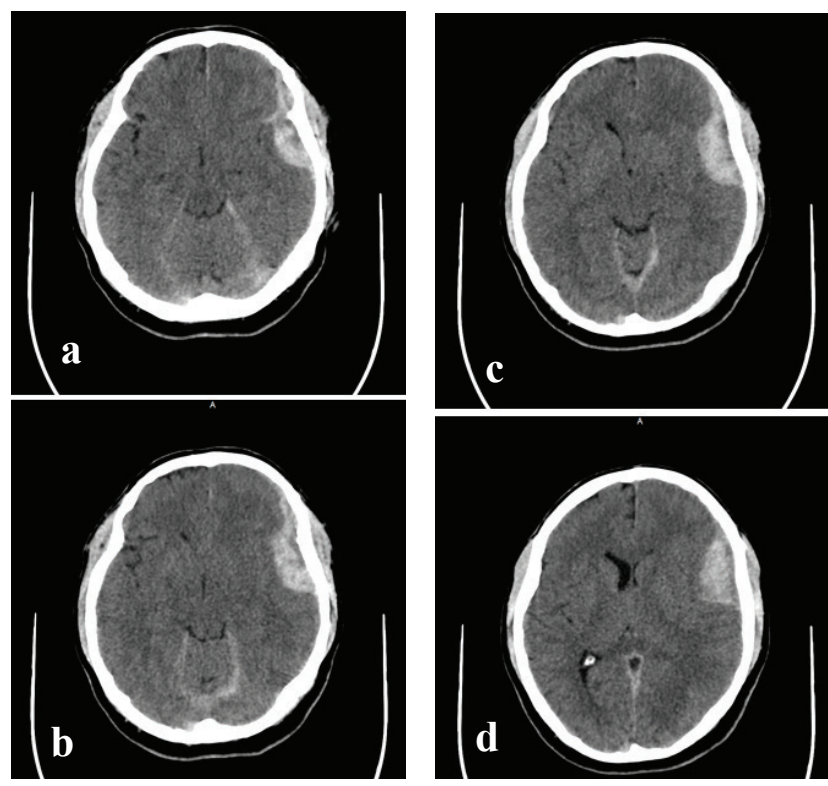

N1

\section{İvadas}

Daugelyje šalių, iš jų ir Lietuvoje, sergamumas pirminiais galvos smegenų navikais nuolat didejja. Centrinès nervų sistemos (CNS) pirminiai navikai sudaro apie 2 proc. suaugusių žmonių onkologinių ligų. Pasaulinès sveikatos organizacijos (PSO) duomenimis, sergamumas pirminiais galvos smegenų navikais skirtingose šalyse svyruoja nuo 5 iki 15,8 atvejų 100000 gyventojų per metus. Lietuvoje sergamumas pirminiais CNS navikais sudaro 11,7 atvejų 100000 gyventojų per metus. Tarp visų pirminių CNS navikų didžiausią grupę, t. y. apie 45-60 proc. visų galvos smegenų navikų, sudaro neuroepitelinio audinio navikai [1-4]. Antroje vietoje pagal dažnumą yra meningiomos, sudarančios 33,8 proc. visu intrakranijinių navikų atvejų [5-7]. Atsižvelgiant ị standartizuotus rodiklius, sergamumas meningiomomis pasaulio mastu siekia nuo 1,28 atvejų, tenkančių 100000 gyventojų iki 7,80 atvejų 100000 gyventojų [8]. Remiantis autopsijos duomenimis, meningioma nustatoma 2,3 proc. mirusiujų
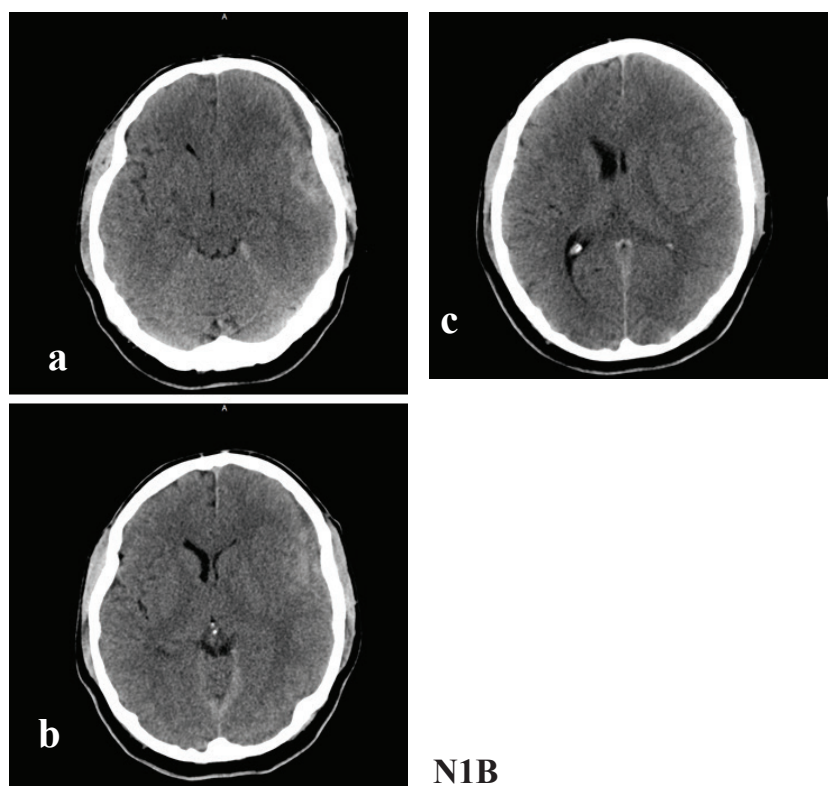

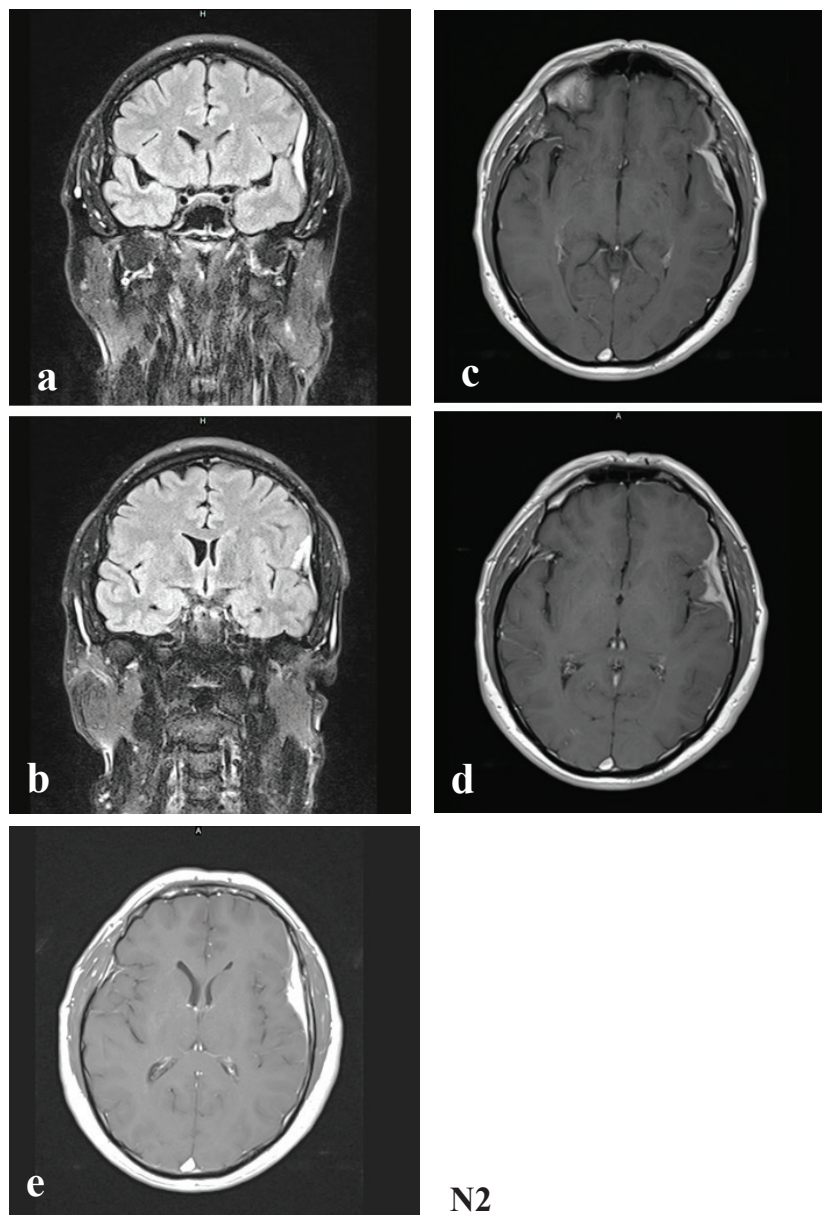

N2

ir 3 proc. vyresnių nei 60 metu žmonių. Aukštas yra sergamumo daugybinėmis meningiomomis rodiklis, siekiantis iki 8 proc. $[9,10]$.

PSO, remdamasi tokiais histologiniais kriterijais kaip ląstelių tipas ir kiekis, mitotinis aktyvumas, nekrozè bei smegenų audinio invazija, suklasifikavo meningiomas pagal tris laipsnius [11]. Atsižvelgiant ị PSO klasifikaciją, gerybinès meningiomos (PSO 1 laipsnio) sudaro 80-90 proc. visu meningiomos atvejų ir pasireiškia keliais galimais histologiniais variantais, kurie neturi atipinès ar anaplastinès meningiomos histologiniu kriterijų. Atipinès meningiomos (PSO 2 laipsnio) sudaro 5-15 proc. visų nustatomų meningiomų. Anaplastinès meningiomos (PSO 3 laipsnio) pasireiškia 1-3 proc. dažniu tarp visų meningiomų. Meningiomų recidyvavimas po operaciju siekia tokius procentinius skaičius: PSO 1 laipsnio - 7-20 proc., PSO 2 laipsnio - 30-40 proc. ir 50-80 proc., sergant PSO 3 laipsnio meningioma [11-14]. Moterims meningiomos susiformuoja dažniau nei vyrams (santykiu tarp moterų ir vyrų 2:1) [5-7], tačiau atipinès ir piktybinès meningiomos dažniau nustatomos vyrams $[10,15]$. Be to, atipinès ir
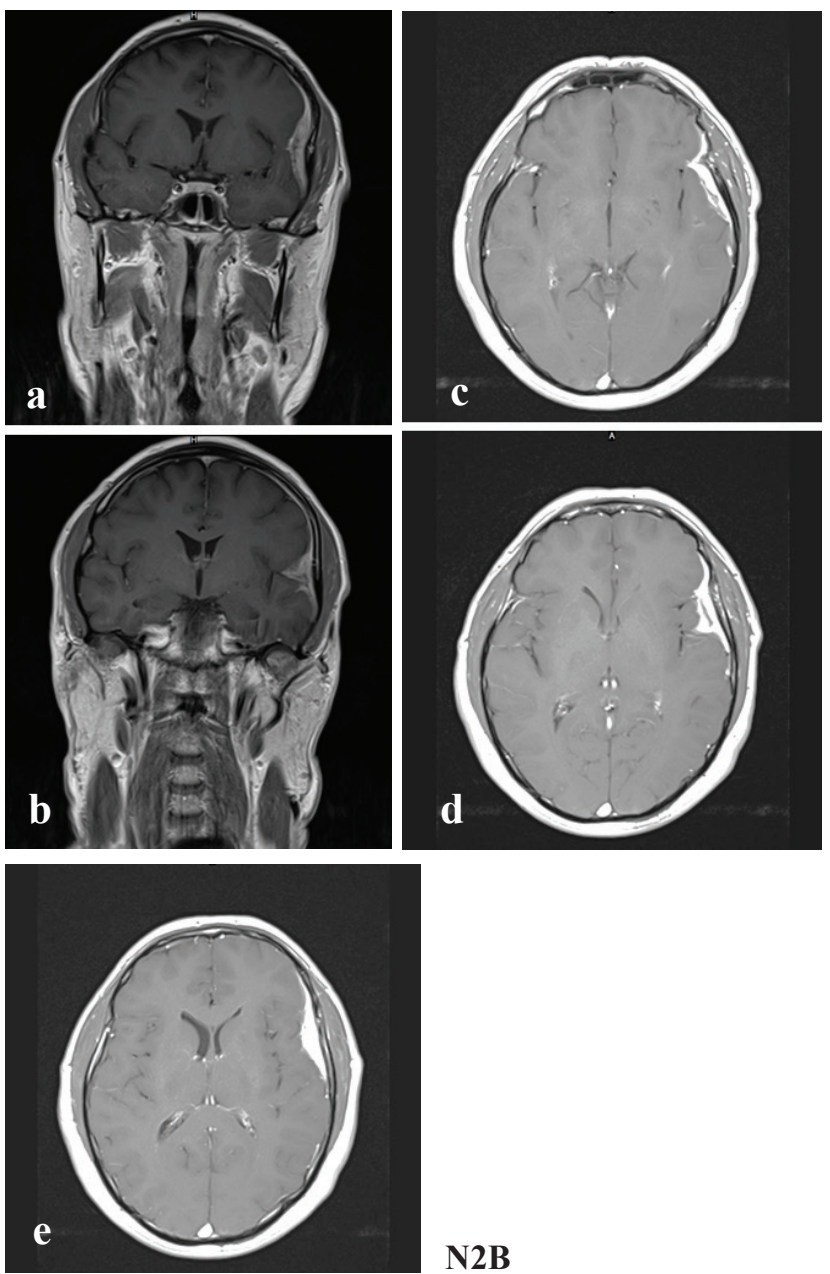

N2B

piktybinès meningiomos ne ispanakalbiu juodaodžių grupėje aptinkamos dažniau $(6,67)$, lyginant su baltaodžių $(5,90)$ ir ispanakalbių grupėmis $(5,94)[16]$. Per studijas, kuriomis siekiama ịvertinti PSO klasifikaciją, nustatyta, jog pacientų, kuriems nustatyta anaplastinè meningioma, išgyvenamumo mediana buvo 2-3 metai, o turinčių gerybinę meningiomą daugiau kaip 10 metų [17]. Ekstraduralinès pirminès meningiomos, neprisitvirtinusios prie kietojo dangalo, nustatomos 1-2 proc. dažniu tarp visų meningiomų [10], o en plaque tipo meningioma sudaro 2-9 proc. visų meningiomų atvejų [18].

Darbo tikslas: pristatyti atipinès en plaque tipo meningiomos klinikinį atvejị.

\section{Klinikinis atvejis}

Ligonis V. S., gimęs 1963 m., susirgo 2016-02-17, kai slidinèdamas kalnuose pajuto stiprų galvos skausmą, po to jautè pykinimą ir vėmè. Dẻl šių nusiskundimų pacientas kreipèsi ị užsienio gydytojus, tačiau jam buvo paskirtas tik gydymas nuo skausmo. Jokių tyrimų atlikta nebuvo. Po 4 
dienų sugrịžęs ị Lietuvą, ligonis kreipèsi ị Klaipėdos universitetinę ligoninę dèl nepraeinančiu galvos skausmų. Pacientas buvo sąmoningas, kritiškas, gerai orientavosi erdvejje, rodiklis pagal Glazgo komos skalę (GKS) -15b. Žmogus valde rankas ir kojas, jèga ịvertinta kaip simetriška (5b.), židininè neurologinè simptomatika nepasireiškè. Cerebralinių bulbarinių nervų pakitimų nenustatyta (CBN n. y.). Buvo atlikta galvos smegenu KT (N1 pav.) (KT 2016-02-22), nustatyta kairès pusès frontoparietotemporaliai subdurinè, apie $40 \mathrm{~cm}^{3}$ apimties hematoma rezorbcijos stadijoje, vidurio linijos dislokacija (VLD) - apie $3 \mathrm{~mm}$. Atlikta kompiuterinès tomografijos angiografija (KTA): aneurizmų nerasta. Buvo spėjama, kad spontaninès subdurinès hematomos fone susiformavusi en plaque tipo meningioma. Ligoniui buvo skirtas standartinis medikamentinis gydymas, taikomas spontaninès subdurinès hematomos atveju. Po 2 mènesiu pacientas stacionarizuotas, kad jam būtų atlikti papildomi tyrimai. Atlikus MRT (N2 pav.) (vaizdai 2016-05-30), nustatyta: kaireje frontototemporaliai, ekstraaksialiai matoma ne visai tolygi, iki $1 \mathrm{~cm}$ ilgio heterogeniška juostelè, ịsiterpianti ị kairiają Silvijos vagą, po kontrasto intensyviai kaupianti kontrastinę medžiagą. Pakitimai diferencijuotini tarp susiformavusių granuliacijų po buvusio pakraujavimo ir navikinių pakitimų, tikslinga sekti MRT, stebint ligos dinamiką.

Dar po 2 mènesių ligonis pakartotinai stacionarizuotas, kad jam būtų atlikti papildomi tyrimai. Po MRT (N3 pav.) (vaizdai 2016-07-21) nustatyta, kad subdurinè hematoma
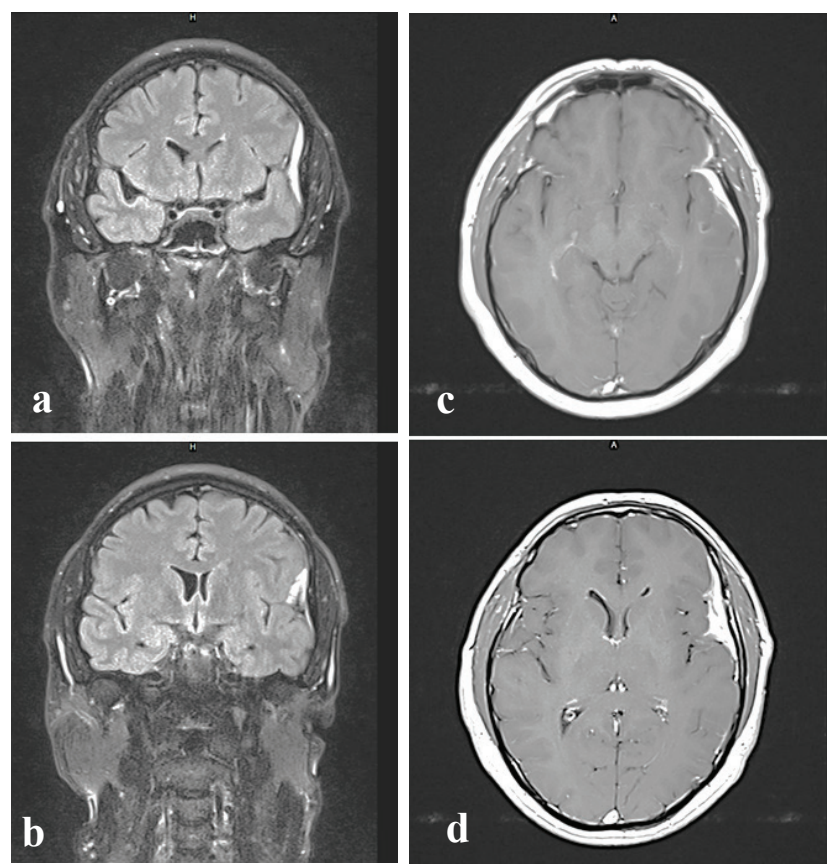

rezorbavosi, tačiau išlieka papildomas darinys frontotemporaliai kairejje pusejje. Aptarus esamus pokyčius ir tyrimo rezultatus, buvo nuspręsta pacientą operuoti dèl ịtariamos en plaque tipo meningiomos. Ligonis buvo operuotas 201607-26. Per operaciją pašalinta iki $3 \mathrm{~cm}$ storị siekianti frontopareitotemporalinès lokalizacijos šliaužianti meningioma, infiltruojanti kietaji smegenų dangalą. Rezekcija vykdyta su kietuoju smegenų dangalu, atliekant duros plastiką. Pathistologinis atsakymas: 16/06071/09 atipinè meningioma, PSO $\mathrm{II}^{\circ}$. Kontrolineje KT po operacijos (N4 pav.) (vaizdai 201607-26) matyti, kad navikas pašalintas, pakraujavimo nėra. Po to taikytas standartinis medikamentinis ir reabilitacinis gydymas. Atliekant kasmetinius kontrolinius MRT stebėjimo tyrimus (N5 ir N6 pav.) (vaizdai 2017-01-17 ir 2019-03-13), naviko recidyvo nepastebeta.

\section{Diskusija}

Kai naudojantis KT ir MRT tiriamos meningiomos, dažniausiai, apie 80-90 proc. atvejų, stebimas tipinis meningiomų vaizdas. Tokioms meningiomoms būdingas vaizdas - aiškiai ribota, homogeniškai kaupianti kontrastą ekstraaksialinè masè, hipointensinè MRT T1W ir hiperintensinè T2W režimais. Toks tipinis vaizdas leidžia radiologui užtikrintai diferencijuoti meningiomą nuo kitų patologijų [3]. Tačiau atipinès naviko histologinès struktūros, o kartais net tipinio histologinio vaizdo atveju, gali būti stebimas ir neiprastas radiologinis meningiomos vaizdas, kuris pasitaiko 15 proc. atvejų ir apsunkina tikslią diagnostiką $[15,19]$.
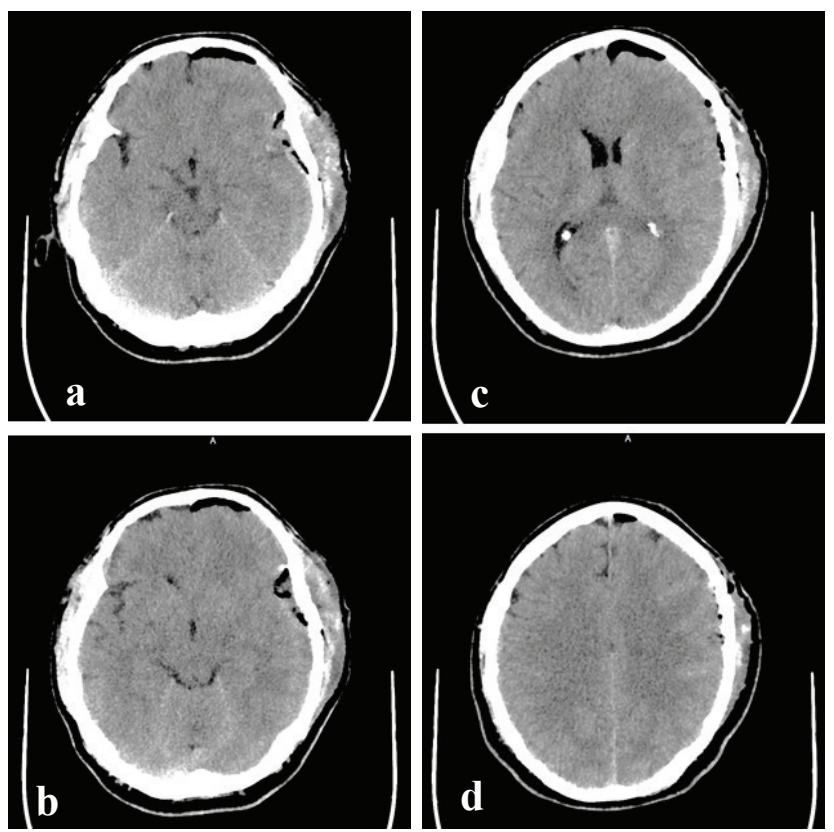

N4 
Dažniausiai netipiškai atrodančią meningiomą reikètų diferencijuoti nuo kitų toliau išvardytų kaupiančių kontrastą ekstraaksialinių darinių, kurie taip pat gali ardyti kaulą: tuberkuliomos, mimikruojančios į en plaque meningiomą, epidurinio galvos smegenų absceso, eozinofilinès granulomos, plazmocitomos, aneurizminès kaulo cistos, dermoidinių ir epidermoidinių cistų $[20,21]$. Šiame straipsnyje aptariamu atveju, en plaque meningiomą teko diferencijuoti nuo subdurinio pakraujavimo.

En plaque tipo meningioma yra retas biologinis meningiomos tipas, kuris infiltruoja kietaji smegenų dangalą ir gali būti susijęs su kaulo hiperostoze, tačiau ne visada. Tik 13-49 proc. en plaque tipo meningiomos atvejų pasireiškia kartu su kaulo hiperostoze [21]. En plaque tipo meningioma daugiausia plinta palei sphenoidinį sparną [22]. Moterims ji pasitaiko 3-6 kartus dažniau nei vyrams ir pasireiškia šeštąseptintą gyvenimo dešimtmetị [23].

H. W. Cushing apibūdino en plaque tipo meningiomą kaip ,plokščiu būdu tarsi besitęsiantis kilimas plintantị naviką“ $[24,25]$. En plaque tipo meningioma - tai specifinis klinikopatologinis vienetas, kuris nors ir yra pasižymintis vietiniu invaziškumu, tačiau PSO paprastai priskiriamas prie $\mathrm{I}^{\circ}[26]$. Netipinès meningiomos, ypač en plaque tipo meningiomos, neišsiskiriančios masès efektu ir kaulo sustorèjimu, kelia iššūkị nustatant diagnozę [19]. Atipinio radiologinio meningiomos vaizdo atveju, atliekant diferencinę diagnostiką, gali būti pasitelkiami papildomi tyrimai, pvz.: magnetinio rezonanso (MR) spektroskopija,
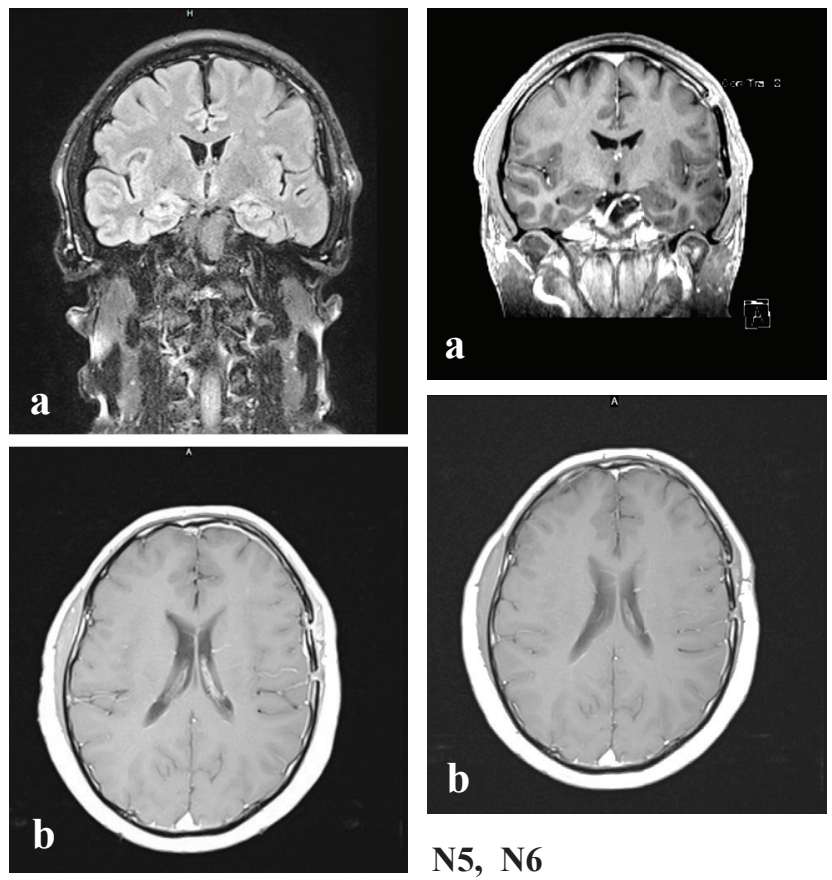

N5, N6 difuzinis ir perfuzinis MRT, pozitronų emisijos tomografija (PET) [10,20,27]. Kartais, kad būtų nustatyta tiksli diagnozé, reikia atlikti tyrimus, stebint ligos dinamiką.

\section{Išvados}

Meningioma - dažniausia gerybinis galvos arba nugaros smegenų navikas, susiformuojantis iš arachnoidinio dangalo meningotelinių ląstelių. Meningiomos pagal dažnumą tarp pirminių CNS navikų užima antrą vietą ir sudaro 33,8 proc. visų intrakranijinių navikų. Nors $80-90$ proc. atvejų stebimas tipinis KT ir MRT meningiomų vaizdas, tačiau iki 15 proc. atvejų gali būti matomas ir neịprastas radiologinis meningiomos vaizdas, ypač tuomet, kai stebima en plaque tipo meningioma. Tai apsunkina tikslią naviko diagnostiką ir kelia nemažą iššūkị tiek nustatant diagnozę, tiek pasirenkant gydymo taktiką. Nustatyti en plaque tipo miningiomą gali padèti papildomi tyrimai: MR spektroskopija, difuzinis ir perfuzinis MRT, PET. Išliekant neaiškumams, tyrimus tikslinga atlikti, stebint ligos dinamiką. Nustačius en plaque tipo meningiomą ir atlikus radikalų naviko pašalinimą su kietojo dangalo plastika, galima užtikrinti ilgalaikę remisiją arba visišką ligonio pasveikimą.

\section{Literatūra}

1. Jaškevičienė V., Šidiškis J. Centrinès nervų sistemos navikai: paplitimas, klasifikacija, klinika, apskaita. Neurologijos seminarai, 2002;1-2:46-54.

2. Osborne RH, Houben MP, Tijssen CC. et al. The genetic epidemiology of glioma. Neurology 2001;57:1751-1755.

3. Gudinavičienè I., Pranys D., Juozaitytė E. Gliomų morfologijos ir biologijos ịtaka jų prognozei. Medicina, 2004;40(2):112-120.

4. Shahmohammadi MR, Javadian H, Asgari A, Khoshnoud RJ. Glioblastoma simultaneously present with adjacent meningioma: case report. ICNSJ 2016;3(1):54-58.

5. Krajevaitè I., Gleiznienè R. Meningiomos radiologinè diagnostika. Neurologijos seminarai, 2009;13,4(42):207-211.

6. Wiemels J, Wrensch M, Claus EB. Epidemiology and etiology of meningioma. Journal of Neuro-Oncology 2010;99(3):307314.

7. Menon G, Nair S, Sudhir J, Rao BR, Mathew A, Bahuleyan B. Childhood and adolescent meningiomas: a report of 38 cases and review of literature. Acta Neurochir, Wien. 2009;151:239244.

8. Baldi I, Engelhardt J, Bonnet C, Bauchet L, Berteaud E, Grüber A, Loiseau H. Epidemiology of meningiomas. Neurochirurgie 2018 March;64(1):5-14.

9. Nakasu S, Hirano A, Shimura T, Llena JF. Incidental meningiomas in autopsy study. Surg Neurol 1987;27(4):319-22.

10. O'Leary S, Adams WM, Parrish RW. et al. Atypical imaging appearances of intracranial meningiomas. Clinical Radiology 2007;62:10-17. 
11. Louis DN, Ohgaki H, Wiestler OD, Cavenee WK, Burger PC, Jouvet A. et al. The 2007 WHO classification of tumours of the central nervous system. Acta Neuropathol 2007;114(2):97-109.

12. Fathi AR, Roelcke U. Meningioma. Curr Neurol Neurosci Rep 2013 Apr;13(4):337.

13. Detti B, Scoccianti S, Di Cataldo V, Monteleone E, Cipressi S, Bordi L. et al. Atypical and malignant meningioma: outcome and prognostic factors in 68 irradiated patients. J Neurooncol 2013 Dec;115(3):421-427.

14. Perry A, Stafford SL, Scheithauer BW. et al. Meningioma grading: an analysis of histologic parameters. Am J Surg Pathol 1997;21:1455-1465.

15. Campbell BA, Jhamb A, Maguire JA. et al. Meningiomas in 2009 controversies and future challenges. Am J Clin Oncol 2009;32:73-85.

16. CBTRUS. CBTRUS statistical report: primary brain and central nervous system tumors diagnosed in eighteen states in 2002-2006. Hinsdale, IL;2009-2010. Prieiga per internetą: www.cbtrus.org.

17. Yang SY, Park CK, Park SH, Kim DG, Chung YS, Jung HW. Atypical and anaplastic meningiomas: prognostic implications of clinicopathological features. J Neurol Neurosurg Psychiatry 2008;79(5):574-80.

18. Tirtaprawita N, Wiradharma W, Yunus Y, July J. The key role of MRI modalities in en plaque meningioma. Medicinus 2017;6(2):50.

19. Buetow MP, Buetow PC, Smirniotopoulos JG. Typical, atypical, and misleading features in meningioma. RadioGraphics 1991;11:1087-1106.

20. Gleiznienė R., Vidžiūnaitė A., Kudžmaitė M. Atipinis radiologinis meningiomos vaizdas: klinikinis atvejis. Neurologijos seminarai, 2011;15(49):198-202.

21. Cucu AI, Turliuc DM, Sava ARC, Dumitrescu GF, Turliuc Ş, Costea CF. Falx cerebri tuberculoma mimicking en plaque meningioma - case report. Romanian Neurosurgery 2016;XXX 2:209-213.

22. Saat R, Lempinen LJ, Laulajainen-Hongisto A, Markkola A, Jero J. An en plaque meningioma of the temporal bone, com- plicating with a cholesteatoma, chronic otitis media and an intracranial abscess. Ann Otolaryngol Rhinol 2015;2(7):1050.

23. Schick U, Bleyen J, Bani A, Hassler W. Management of meningiomas en plaque of the sphenoid wing. J Neurosurg 2006;104:208-14.

24. Yamada S, Kawai S, Yonezawa T, Masui K, Nishi N, Fujiwara K. Cervical extradural en-plaque meningioma. Neurol Med Chir, Tokyo. 2007;47:36-39.

25. Cushing H, Eisenhardt L. Meningioma of the sphenoidal ridge. Meningiomas: Their Classification, Regional Behaviour, Life History and Surgical End Results. Hafner Publishing (New York). 1969;342-359.

26. Basu K, Majumdar K, Chatterjee U, Ganguli M, Chatterjee S. En plaque meningioma with angioinvasion. Indian J Pathol Microbiol 2010;53:319-321.

27. Weber DC, Lovblad KO, Rogers L. New pathology classification, imagery techniques and prospective trials for meningiomas: the future looks bright. Current Opinion in Neurology 2010;23:563-570.

\section{ATYPICAL EN-PLAQUE TYPE MENINGIOMA. CLINICAL CASE D. Aleksandrov}

Keywords: atypical radiological view, en-plaque meningioma. Summary

Meningiomas occupy the second place comparing them with the other most common primary CNS tumors, accounting for $33.8 \%$ cases of all intracranial tumors. Although in $80-90 \%$ cases a typical picture of CT and MRI of meningiomas is observed, in up to $15 \%$ cases, an atypical image can also be seen. En-plaque meningiomas account for $2-9 \%$ meningioma cases, but due to the specificity of their image, they constitute a considerable challenge while diagnosing and selecting the treatment tactics. The article describes a clinical case of a 53-years-old Lithuanian man who suffers from an en-plaque type meningioma.

Correspondence to: dr.aleksandrov@gmail.com

Gauta 2019-10-22 